Article

\title{
Synthesis and Crystal Structure of
}

Bis(2-phenylpyridine-C,N')-bis(acetonitrile) iridium(III)hexafluorophosphate Showing Three Anion/Cation Couples in the Asymmetric Unit

\author{
Elisa Fresta ${ }^{1}\left(\mathbb{D}\right.$, Marco Milanesio $^{2}$, Giorgio Volpi $^{3}$, Claudia Barolo $^{3} \mathbb{D}$ and \\ Eleonora Conterosito $2, *$ (iD) \\ 1 IMDEA Materials Institute, Calle Eric Kandel 2, Getafe, E-28906 Getafe, Madrid, Spain; \\ elisa.fresta@imdea.org \\ 2 Department of Science and Technological Innovation, University of Eastern Piedmont, viale T. Michel, 11, \\ 15121 Alessandria, Italy; marco.milanesio@unipmn.it \\ 3 Department of Chemistry, NIS Interdepartmental Centre and INSTM Reference Centre, \\ Università degli Studi di Torino, Via Pietro Giuria 7, 10125 Torino, Italy; \\ giorgio.volpi@unito.it (G.V.); claudia.barolo@unito.it (C.B.) \\ * Correspondence: eleonora.conterosito@uniupo.it
}

Received: 18 October 2019; Accepted: 19 November 2019; Published: 25 November 2019

check for updates

\begin{abstract}
The title compound bis(2-phenylpyridine-C, $\mathrm{N}^{\prime}$ )-bis(acetonitrile)iridium(III)hexafluorophosphate, a six-coordinate iridium(III) complex, crystallizes in the $P-1$ space group. Iridium is in a distorted octahedral $(n=6)$ coordination with the $\mathrm{N}, \mathrm{C}^{\prime}$ atoms of two phenylpyridine and the $\mathrm{N}$ atoms of two acetonitrile ligands. The peculiarity of this structure is that three independent moieties of the title compound and three $\mathrm{PF}_{6}{ }^{-}$anions, to counterbalance the charge, are observed in the asymmetric unit and this is a rather uncommon fact among the Cambridge Crystallographic Database (CSD) entries. The three couples are almost identical conformers with very similar torsional angles. The packing, symmetry, and space group were accurately analyzed and described also by means of Hirshfeld surface analysis, which is able to underline subtle differences among the three anion/cation couples in the asymmetric unit. The driving force of the packing is the clustering of the aromatic rings and the maximization of acetonitrile: $\mathrm{PF}_{6}{ }^{-}$interactions. The asymmetry of the cluster is the cause of the unusual number of moieties in the asymmetric unit.
\end{abstract}

Keywords: phenylpyridine Ir complex; crystal packing; single crystal X-ray diffraction; CCDC database; Hirshfeld surface

\section{Introduction}

The metallation reactions of organic nitrogen compounds with iridium(III) to form a metal-carbon bond have been widely reported [1-4]. Most studies have dealt with iridium(III) complexes containing cyclometalated ligands such as 2-phenylpyridine and its derivatives. In general, the use of cyclometalated ligands enables the formation of neutral or mono-cationic $\operatorname{Ir}(\mathrm{III})$ complexes which are advantageous for lighting technologies [5-8]. In these complexes, the 2-phenylpyridine loses one proton and coordinates to a metal ion through the carbon and nitrogen atoms, thus forming a five-membered chelate ring. The dichloro-bridged iridium(III) dimer complex $\left[\left(\mathrm{C}^{\wedge} \mathrm{N}\right)_{2} \operatorname{Ir}(\mu-C l)\right]_{2}$ is prepared by heating hydrated iridium trichloride and 2-phenylpyridine. The $\left[\left(\mathrm{C}^{\wedge} \mathrm{N}\right)_{2} \operatorname{Ir}(\mu-C l)\right]_{2}$ is typically employed, as a precursor, to obtain the corresponding $\left[\left(\mathrm{C}^{\wedge} \mathrm{N}\right)_{2} \operatorname{Ir}\left(\mathrm{N}^{\wedge} N\right)_{2}\right]^{+}$complexes by reaction with $\left(\mathrm{N}^{\wedge} \mathrm{N}\right)$ general ligands such as bipyridine, phenanthroline, etc. 
Iridium(III) phenylpyridine-based complexes play a pivotal role in applications such as light emitting devices [9-11] and luminescent biological labels [12], owing to their high quantum yields, their sound electrochemical stability and reversibility, their well-known chemistry, and their easy color tunability [13]. Similarly to the widely investigated ruthenium(II) complexes [14], their emission is often arising from a triplet metal-to-ligand charge transfer $\left({ }^{3} \mathrm{MLCT}\right)$ excited state, or by mixed ${ }^{3}$ MLCT-ligand centered (LC) states. However, unlike the ruthenium analogues, iridium(III) complexes are highly tunable in the color of the emission. Indeed, by selecting suitable substituents on the phenylpyridine ligands, the band-gap of the complexes can be tuned from the red to the blue-greenish region of the visible spectrum [15]. The great interest in the achievement and synthesis of rationally designed phenylpyridine ligands resulted in a large number of solved crystal structures of a variety of phenylpyridine complexes with different charges, metals, and counter ions.

We present in this study a structure obtained by serendipity; indeed, the newly synthesized complex [Ir(3-(2-methoxyphenyl)-5-methyl-1-(6-methylpyridin-2-yl)H-imidazo[1,5-a]pyridine) (2-phenylpyridine) $)_{2} \mathrm{PF}_{6}$ was obtained in the form of a yellow powder [16] and was dissolved in an acetonitrile solution employed for cyclic voltammetry measurements. As such, the solution also contained tetrabutylammonium hexafluorophosphate. In an attempt to recover the complex, the solution was partially dried in a rotary evaporator and yellow crystals were formed, which were washed with water and diethyl ether. However, during this process acetonitrile replaced the -(2-methoxyphenyl)-5-methyl-1-(6-methylpyridin-2-yl)H-imidazo[1,5-a]pyridine ligand in a solvent-ligand exchange reaction [16] and the title compound was obtained in a very crystalline form by a route different from those present in the literature, whose structure had been solved at low temperature [17].

The title compound crystal packing is quite uncommon among the Cambridge Crystallographic Database (CSD) entries [18]. In fact bis(2-phenylpyridine-C, $\mathrm{N}^{\prime}$ )-bis(acetonitrile)iridium(III) hexafluorophosphate called $\left[\operatorname{Ir}(\mathrm{ppy})_{2}(\mathrm{acn})_{2}\right]^{+} / \mathrm{PF}_{6}{ }^{-}$from now on, crystallized in the $P-1$ space group with three anion/cation couples in the asymmetric unit. Structures with $Z^{\prime}$ (the number of moieties in the asymmetric unit) higher than one are quite a crystallographic oddity, which has recently attracted attention in the field of crystal structure prediction and study of the intermolecular interactions in crystal packing [18-22]. [Ir(ppy $\left.)_{2}(\mathrm{acn})_{2}\right]^{+} / \mathrm{PF}_{6}{ }^{-}$was analyzed using the same approach already used for other complexes [23], organic compounds [24], and salts [25], calculating Hirshfeld surfaces [26-29] to evaluate the intermolecular interactions and their differences among the similar coordination compounds [30,31].

\section{Materials and Methods}

\subsection{Synthesis and Crystallization}

The complex was synthesized following procedures reported in the literature (Scheme 1), which involved a two-step synthesis to obtain the dimer $\left[\left(\mathrm{C}^{\wedge} \mathrm{N}\right)_{2} \operatorname{Ir}(\mu-C l)\right]_{2}$ [3], followed by a complexation with the suitable $\mathrm{N}^{\wedge} \mathrm{N}$ ligand [8]. In our case, $\left[\left(\mathrm{C}^{\wedge} \mathrm{N}\right)_{2} \operatorname{Ir}(\mu-C l)\right]_{2}(0.1 \mathrm{~g}, 0.092 \mathrm{mmol})$ was put in a round bottomed flask containing $20 \mathrm{~mL}$ of dichloromethane:methanol 1:1 v/v. The solution was stirred under nitrogen until complete dissolution of the dimer. The ligand 3-(2-methoxyphenyl)-5-methyl-1-(6-methylpyridin-2-yl)H-imidazo[1,5-a]pyridine (0.04 g, 0.12 mmol) was subsequently added and stirred under reflux for approximately two hours. Then, the solution was cooled to room temperature and dried with a rotary evaporator. 

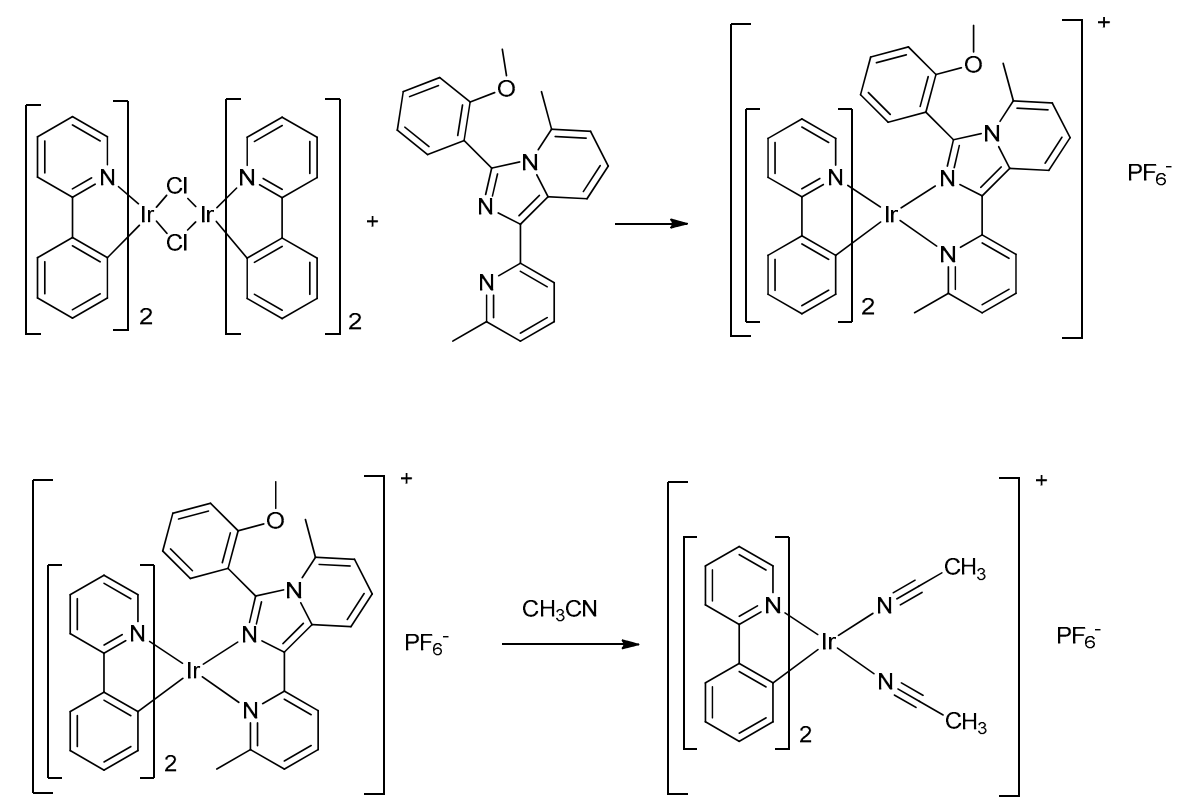

Scheme 1. Reaction scheme for the formation of $\left[\operatorname{Ir}(\mathrm{ppy})_{2}(\mathrm{acn})_{2}\right]^{+} / \mathrm{PF}_{6}{ }^{-}$.

The complex was washed with ethyl ether to remove the excess of ligand and was dissolved in dichloromethane, then centrifuged and filtered to eliminate the eventual residual dimer. In a following step, the complex was dissolved in $1 \mathrm{~mL}$ of methanol and a saturated solution of $\mathrm{NH}_{4} \mathrm{PF}_{6}$ in methanol was added, yielding a yellow precipitate. The powder was dried under vacuum. Then, the complex was dissolved in 1-2 mL of methanol 50:50, and a saturated solution of $\mathrm{NH}_{4} \mathrm{PF}_{6}$ in methanol was added. A yellow crystalline precipitate $(0.04 \mathrm{~g}, 0.069 \mathrm{mmol}, 75 \%$ yield $)$ was formed. This was collected, dried with ethyl ether, and stored under vacuum.

The so-obtained [Ir(3-(2-methoxyphenyl)-5-methyl-1-(6-methylpyridin-2-yl)H-imidazo[1,5-a] pyridine)(2-phenylpyridine) $\left.)_{2}\right] \mathrm{PF}_{6}$ was dissolved in an acetonitrile solution $(10 \mathrm{~mL})$ together with tetrabutylammonium hexafluorophosphate $(0.1 \mathrm{M})$, and cyclic voltammetry was performed in the range -2 to $2 \mathrm{~V}$. Subsequently, the complex was isolated by drying the solution, yielding yellow crystals that were washed with water and diethyl ether. The isolated product was Bis(2-phenylpyridine-C,N')-bis(acetonitrile)iridium(III)hexafluorophosphate, $\left[\operatorname{Ir}(\text { ppy })_{2}(\text { acn })_{2}\right]^{+} / \mathrm{PF}_{6}{ }^{-}$.

\subsection{Structural Study}

Diffraction data were recorded with an Oxford Xcalibur CCD area detector (Oxford Diffraction, Abingdon-on-Thames, United Kingdom) diffractometer, using graphite monochromatized Mo-K $\alpha$ $(\lambda=0.71069 \AA)$ radiation equipped with a Sapphire 3 CCD detector. The compound crystallized in small needles. One of these crystals was chosen and mounted on the diffractometer for the data collection, which was performed at room temperature. Although the small size hampers the possibility of measuring diffraction data at high resolution, solving and refining the structure was possible, keeping the data up to $0.9 \AA$ resolution. Diffraction data were treated using CrysAlisPro (Rigaku Oxford Diffraction, CrysAlisPro Software system, version 1.171.38.46, Rigaku Corporation, Wroclaw, Poland) [32]. After the space group determination, structure solution was performed by direct methods using SIR2014 (Istituto di Cristallografia IC-CNR, version 2014, Bari, Italy) [33] and then refined using SHELXL (University of Göttingen, version 2013, Göttingen, Germany) [34] by Fourier synthesis. The disordered $\mathrm{PF}_{6}{ }^{-}$anions were treated using the commands SADI and DELU. RIGU and ISOR restraints were used on the phenylpyridine rings. Hirshfeld surfaces were calculated using Crystal Explorer 17.5 (University of Western Australia, version 17.5, Crawley, Australia) [35]. Molecular graphics were produced using Mercury (Cambridge Crystallographic Data Centre (CCDC), Mercury CSD 3.10.3 (Build 206425), Cambridge, United Kingdom) [36]. 
Crystal data, data collection, and structure refinement details for $\left[\operatorname{Ir}(\mathrm{ppy})_{2}(\mathrm{acn})_{2}\right]^{+} / \mathrm{PF}_{6}{ }^{-}$are summarized in Tables 1 and 2. The Cambridge Crystallographic Data Centre (CCDC)-1959869 contains the supplementary crystallographic data for this paper. The checkCIF gives no alert A but some alert $\mathrm{B}$ that are unavoidable given the small crystal size which causes weak diffraction spots and lower resolution. These data can be obtained free of charge from The Cambridge Crystallographic Data Centre www.ccdc.cam.ac.uk/data_request/cif. (See Supplementary Materials).

\section{Results}

The title compound, being cationic, crystallizes with $\mathrm{PF}_{6}{ }^{-}$in space group $P-1$ with three cation/anion couples in the asymmetric unit $\left(Z=12\right.$ and $\left.Z^{\prime}=6\right)$ as can be seen in Figure 1. Iridium is in a distorted octahedral $(n=6)$ coordination with the $N, C^{\prime}$ atoms of two phenylpyridine and the $\mathrm{N}$ atoms of two acetonitrile ligands. The three coordination compounds are almost identical conformers with very similar torsional angles, as can be seen in Figure 2 by superimposing them. The average Ir-N coordination length is $2.032 \AA$ ( $2.000 \AA$ for the phenylpyridine and $2.094 \AA$ for the acetonitrile groups). The comparison with the literature structure [17] measured at low temperature showed that the cell expands mostly along the $\mathrm{b}$ axis while the a and $\mathrm{c}$ axis show a very small shrinkage (Table 1 ) when increasing the temperature. The increase of the thermal motion primarily affects the $\mathrm{PF}_{6}{ }^{-}$anions that are freer to rotate at room temperature, as expected.

Table 1. Comparison of the unit cell parameters for the structure at high and low temperature.

\begin{tabular}{ccc}
\hline Unit Cell Parameters & Lengths of the Cell Edges (Å) & Angles (Degree) \\
\hline Low temperature (172 K) & a 8.870(1) b 18.131(3) c 25.655(4) & $\alpha 93.993(2)^{\circ} \beta 96.938(2)^{\circ} \gamma 93.926(2)^{\circ}$ \\
\hline Room temperature (293K) & a 8.8635(5) b 18.186(1) c 25.624(2) & $\alpha 93.582(5)^{\circ} \beta 96.034(5)^{\circ} \gamma 93.842(5)^{\circ}$ \\
\hline
\end{tabular}

Given the peculiarity of the title compound crystallizing with multiple very similar moieties in the asymmetric unit, the structure was checked for higher symmetry or pseudosymmetry (often a problem in the presence of a complex with heavy metals and bulky ligands mixed with small ones [37]) using PLATON (Utrecht University, Utrecht, The Netherlands) routine ADDSYM and with the program PSEUDO from Bilbao Crystallographic Server [38], but no plausible higher symmetry space group was found. By looking at Figure 3 right, it can be seen that in the packing there is a sort of "tartan" motif where the coordination compounds (named from now on Mol 1, Mol 2, and Mol 3 according to the label of the iridium atom) are forming vertical and horizontal stripes. In more detail, the green molecules (Mol 3) form a sort of "boundary" between layers of alternated blue (Mol 1) and red (Mol 2) molecules. The driving force of the packing seems to be the possibility of clustering the aromatic moieties, and at the same time facilitating the direct interaction of the acetonitrile ligands with the $\mathrm{PF}_{6}{ }^{-}$anions (named from now on PF6 1, PF6 2, and PF6 3 according to the label of the phosphorus atom) (Figure 4). 


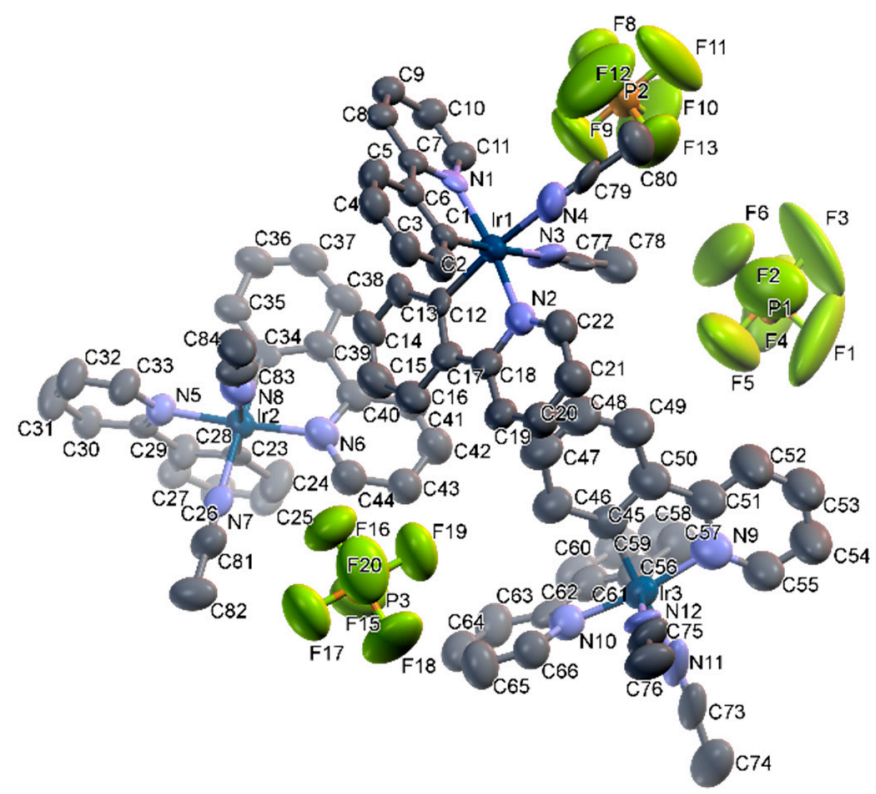

Figure 1. Structure model of the asymmetric unit of $\left[\operatorname{Ir}(\mathrm{ppy})_{2}(\mathrm{acn})_{2}\right]^{+} / \mathrm{PF}_{6}{ }^{-}$.
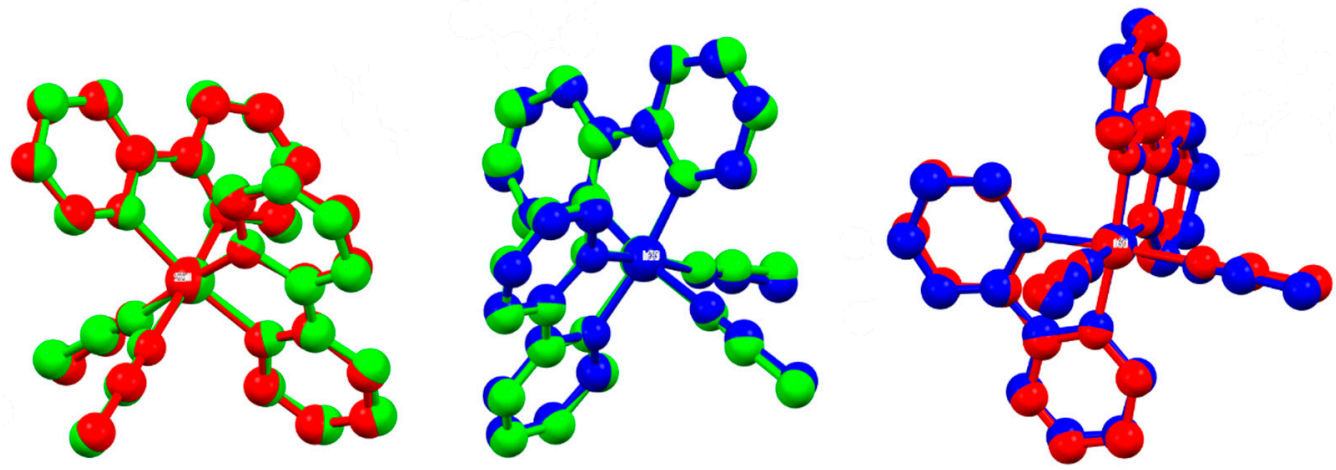

Figure 2. Superposition of the coordination compound by couples (left) Mol 1 and Mol 2; (center) Mol 1 and Mol 3; (right) Mol 2 and Mol 3.
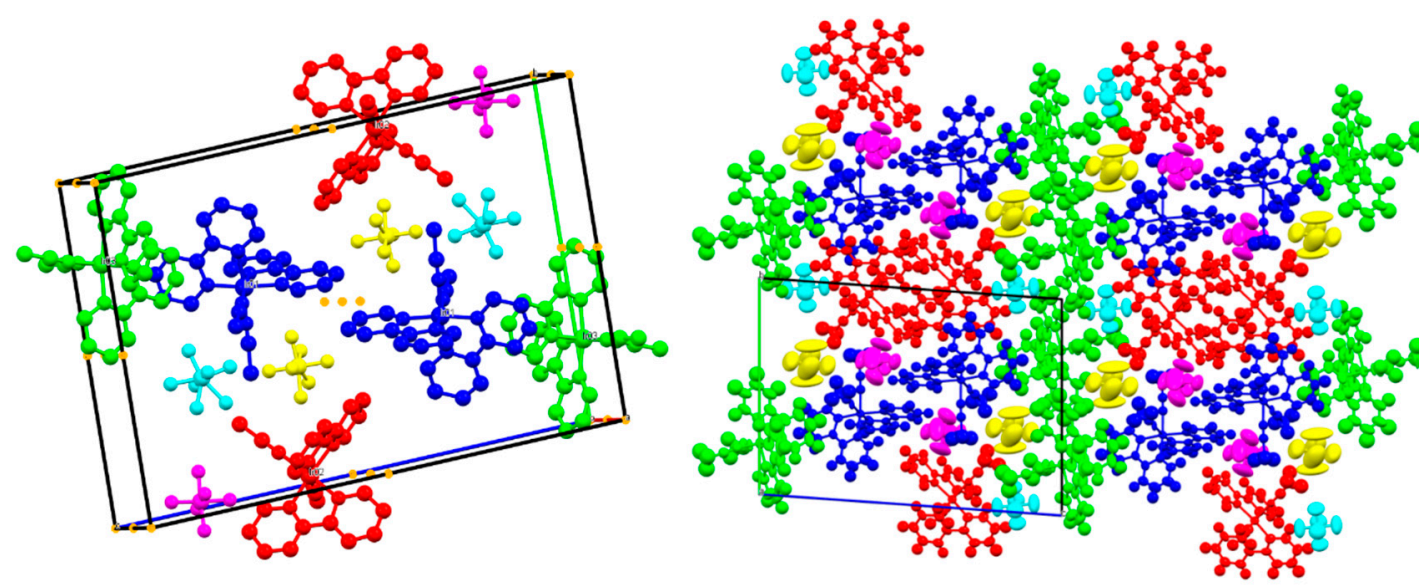

Figure 3. Representation of the unit cell (left) and crystal packing (right) with symmetry equivalent moieties highlighted by different colors: Mol 1 blue; Mol 2 red; Mol 3 green; PF6 1 yellow; PF6 2 magenta; PF6 3 light blue. 


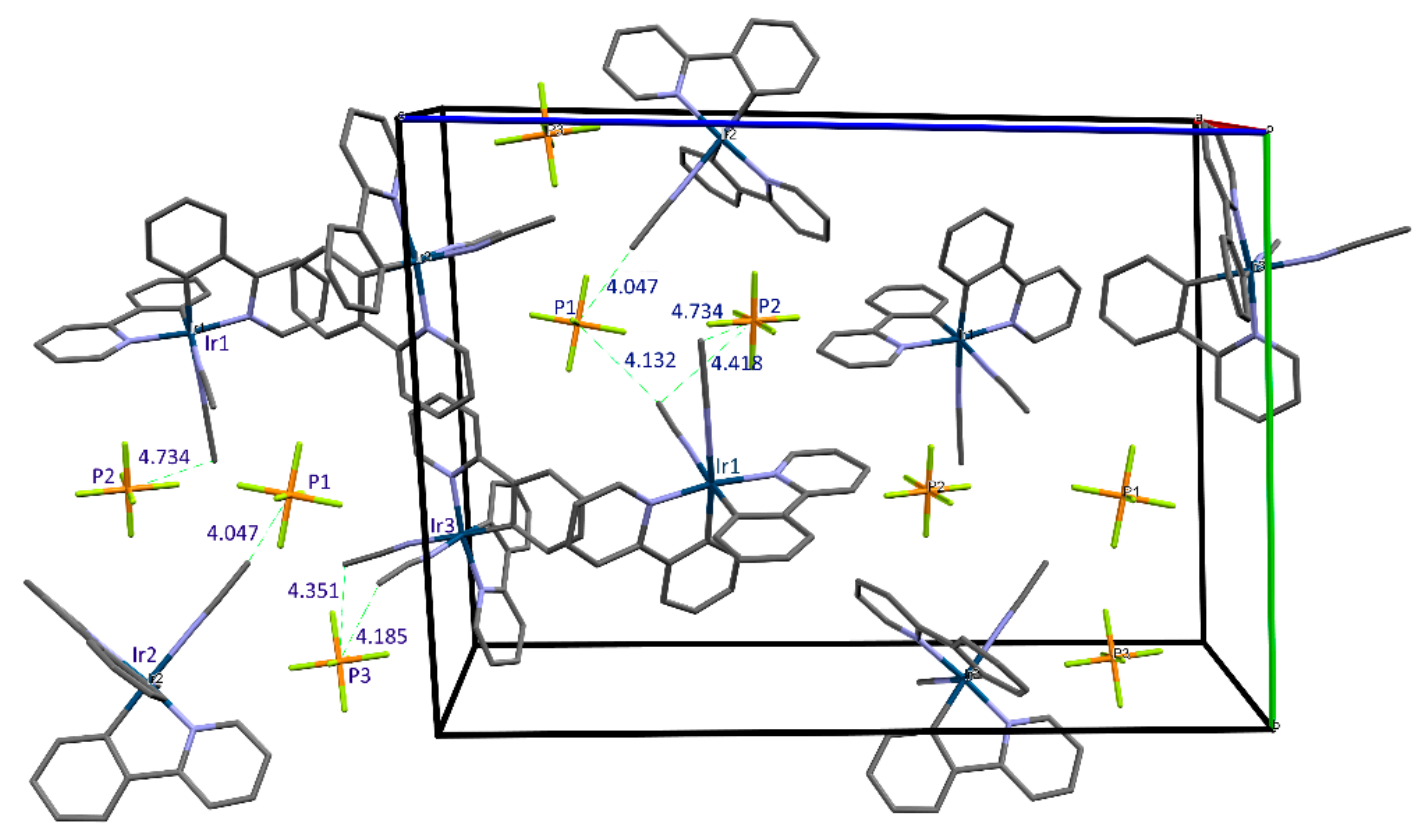

Figure 4. Representation of the packing evidencing the $\mathrm{ACN}-\mathrm{PF}_{6}{ }^{-}$distances.

\section{Discussion}

\subsection{Structures with $Z^{\prime}>1$ in the CCDC Database}

Recently, a number of studies on molecular interactions have tried to explain the different reasons that could be behind the crystallization with multiple molecules in the asymmetric unit. Among the possible explanations, there is the convenience of fitting strong molecular interactions in the packing; i.e., the symmetry is sacrificed to obtain lower packing energies [37]. Other reasons could be simply an odd shape of the molecule, the presence of pseudosymmetry or disorder, temperature and kinetic effects [18], polymorphism, and co-crystallization [19]. In the CSD database (version 5.39 February 2018 update) only 4157 structures with determined 3D coordinates and $Z^{\prime}=3$ are reported, and only 1255 of these are in the $P-1$ space group. Among these, only 468 have any transition metal in the structure, while there are 1393 structures with transition metals crystallizing with $Z^{\prime}=3$ in any space group. The metal organic phenylpyridine and bipyridine complexes that crystallized with more than one molecule in the asymmetric unit are mostly solvates and hydrates, and usually comprise other larger ligands. Among the 1374 structures archived in the CSD comprising two phenylpyridines and iridium, only 12 entries have $Z^{\prime} \geq 3$ and the ratio decreases if excluding structures with substituents on the phenylpyridine groups (only four entries over 570).

The most similar structures with $Z^{\prime}=3, \operatorname{Ir}(\mathrm{III})$ and two phenylpyridine ligands are XUCBED (bis(2-(2-Pyridyl)phenyl-C,N)-(2,2'-dipyridyl ketone-N,N')-iridium(iii) hexafluorophosphate)) which crystallizes in $P 2_{1} / \mathrm{c}$ and IRETEG ((2-methylpyrrolidine-2-carboxylatate-bis(2-(pyridin-2-yl) phenyl)-iridium(iii) dichloromethane solvate) which crystallizes in $\mathrm{P}_{2}$. These two structures crystallize with three coordination compounds and four $\mathrm{PF}_{6}{ }^{-}$anions or one dichloromethane in the asymmetric unit, respectively. In these two cases, the packing is driven by polar interactions made possible by the carbonyl groups of the 2,2'-dipyridyl, ketone- $\mathrm{N}, \mathrm{N}^{\prime}$, and 2-methylpyrrolidine-2-carboxylate, respectively.

In the CSD there are also similar complexes with high $Z^{\prime}$ numbers including bipyridine and a metal like rhodium, ruthenium, or palladium (IMIFEQ [39], AHISOA [40], GODMAP [41]) and the iron complex tris(2,2'-Bipyridyl)-iron bis(dichloro-dinitroso-iron) (JOHXOT [42]). 
The structure of a similar iridium complex with bipyridine was determined by Laws et al. [43]. This complex crystallized with $\mathrm{PF}_{6}{ }^{-}$in the $\mathrm{C} 2 / \mathrm{c}$ space group with $\mathrm{Z}=4$ and $\mathrm{Z}^{\prime}=0.5$ because the $\operatorname{Ir}(\mathrm{I})$ atom sits on a two-fold axis.

Another complex with iridium, 2-phenyl-5,6-(S,S)-pinenopyridine, and $\mathrm{PF}_{6}{ }^{-}$is reported in the literature by Zheng et al. (EQIXAF) [44].

Some other examples of parent 2,2'-bipyridine complexes with large $Z^{\prime}$ showing peculiar packings feature rhodium, ruthenium, and palladium (CSD codes IMIFEQ (dicarbonyl-(6,6'-dihydroxy-2,2'-bipyridine)-rhodium(i) hexafluoro-antimonate acetone diethyl ether solvate) [39], AHISOA (bis(2,2'-Bipyridine-N,N')-(2-(4-(benzothiazolyl)phenyl)imidazo(4,5-f) $(1,10)$ phenanthroline- $\left.\mathrm{N}, \mathrm{N}^{\prime}\right)$-ruthenium(ii) perchlorate toluene acetonitrile solvate hydrate) [40], GODMAP (bis(2,2'-bipyridine)-(11,12-dichlorodipyrido[3,2-a:2',3'-c]phenazine)-ruthenium chloride dodecahydrate) [41], JOHXOT(tris(2,2'-Bipyridyl)-iron bis(dichloro-dinitroso-iron)) [42]). One ruthenium complex with similar ligands (acetronitrile and bipyridine instead of phenylpyridine) is reported in the literature by Heeg et al. [45] and by $\mathrm{Xu}$ and Huang [46], and has only one complex/solvent couple in the asymmetric unit. In the unit cell, there is the $\mathrm{Ru}^{2+}$ coordination compound and two $\mathrm{PF}_{6}{ }^{-}$ anions to balance the charge. This complex has very similar bond lengths, torsion, and angles, as seen in Figure 5 with a superposition of the two complexes, to $\left[\operatorname{Ir}(\mathrm{ppy})_{2}(\mathrm{acn})_{2}\right]^{+} / \mathrm{PF}_{6}{ }^{-}$, but it crystallizes with a quite simple packing in the $P 2_{1} / \mathrm{n}(\mathrm{C} 2 / \mathrm{c}$ according to $\mathrm{Xu}$ and Huang [32]) space group.

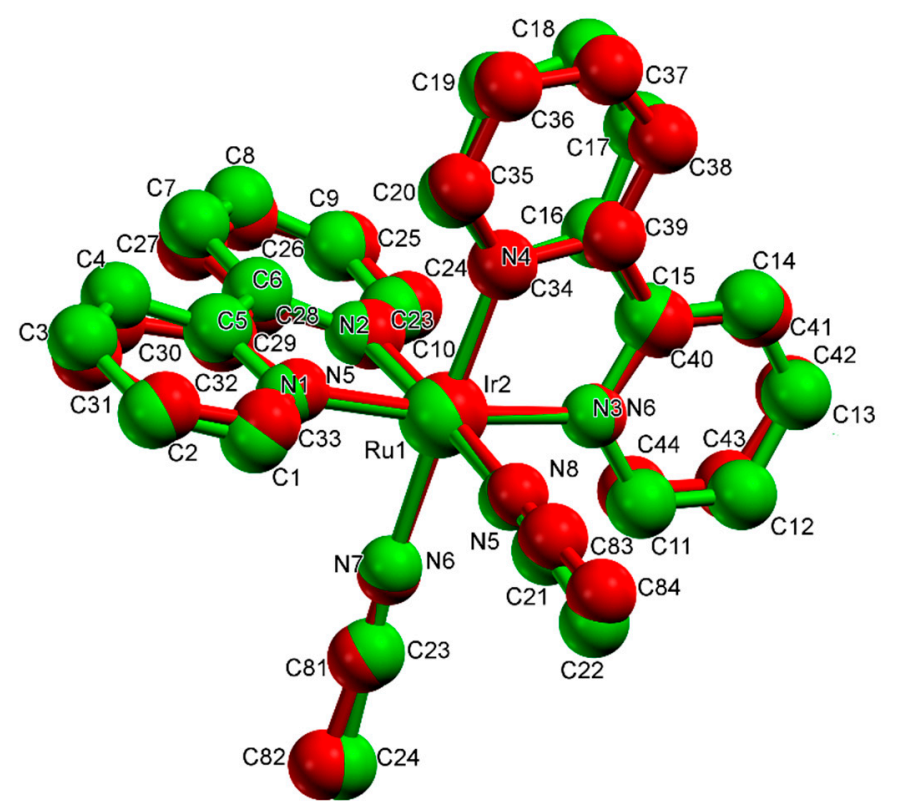

Figure 5. Mol 2 (red) superimposed to the Ruthenium II complex (green).

In the present case, symmetry is sacrificed to better fit and obtain a more favorable packing energy. On one hand, the clustering of the aromatic moieties maximizes the non-polar interactions, and, on the other hand, the direct interaction of the acetonitrile ligands with the $\mathrm{PF}_{6}{ }^{-}$anions is greatly increased. A single couple of $\left[\operatorname{Ir}(\mathrm{ppy})_{2}(\mathrm{acn})_{2}\right]^{+} / \mathrm{PF}_{6}{ }^{-}$evidently cannot fit such motif in the crystal structure. This behavior is probably due to the asymmetry and rigidity of the complex with a very small and polar acetonitrile group and large, much less polar aromatic moieties. It is the cause of the unusual packing with the three couples in the asymmetric unit. 


\subsection{Hirshfeld Surface Analysis}

To better analyze and check similarities between the moieties and packing features of the title compound, the Hirshfeld surfaces were calculated for each moiety in the structure.

Hirshfeld surface analysis shows that the three coordination compounds have the same kind of interactions, but the surroundings of each molecule are not the same. This becomes evident when looking at the Hirsheld surfaces and 2D-fingerprint plots reported in Figures 6-8. The reason for the packing with three moieties in the asymmetric unit can be explained by the fact that a single molecule is not able to fit the symmetry constraints and, at the same time, maximize the above described interactions.
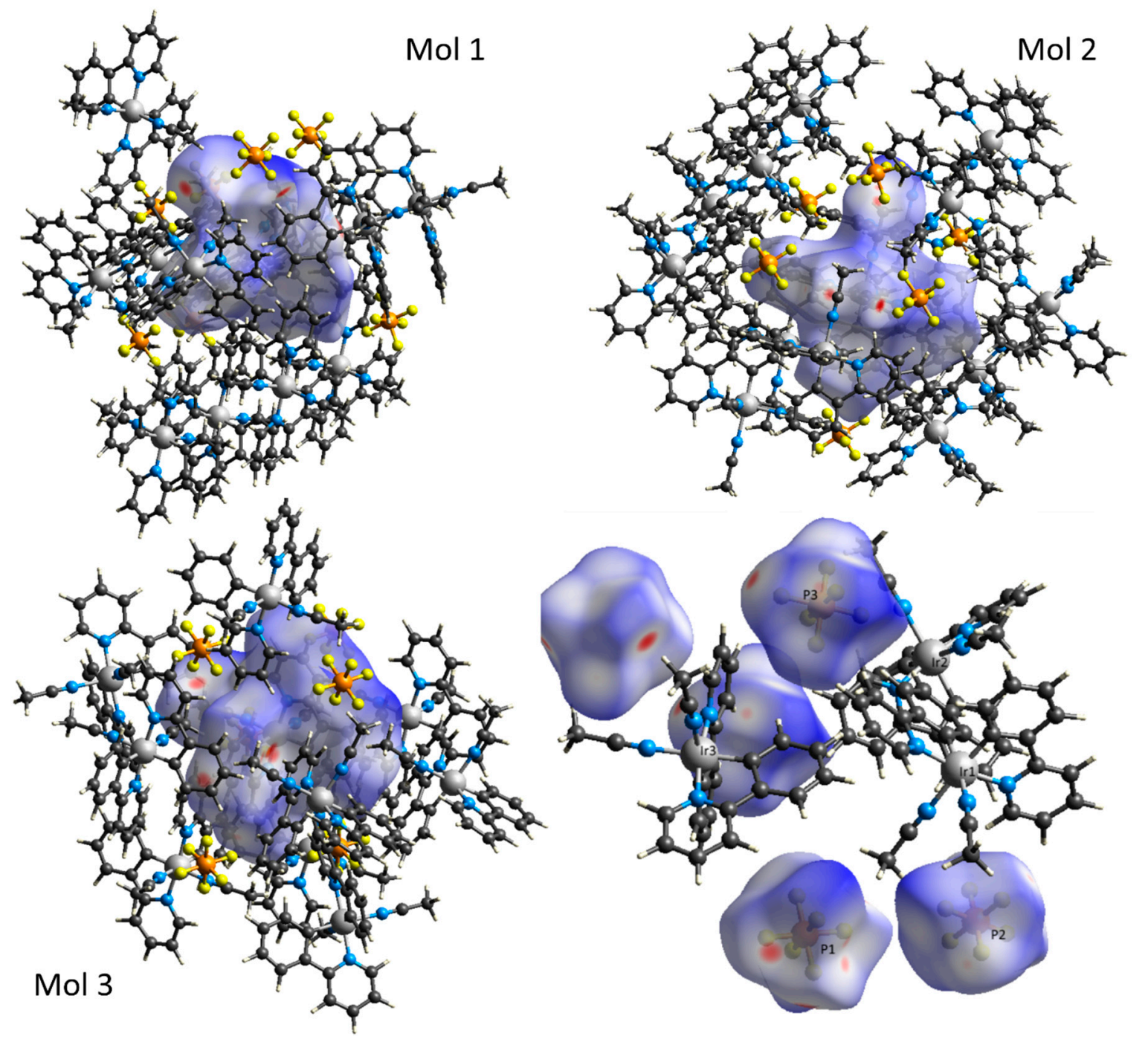

Figure 6. Normalized contact distance $\left(\mathbf{d}_{\text {norm }}\right.$, defined in terms of $\mathbf{d}_{\mathbf{e}}, \mathbf{d}_{\mathbf{i}}$, and the van der Waals radii of the atoms) mapped on the Hirshfeld surface of the three coordination compounds and of $\mathrm{PF}_{6}{ }^{-}$ represented together with the surrounding moieties to visualize the intermolecular interactions (the red dots mark distances between the atoms shorter than sum of van der Waals radii).

The fingerprint plot in Figures 7 and 8 represent the distance from the surface to the nearest nucleus external to the surface $\left(\mathrm{d}_{\mathrm{e}}\right)$ plotted versus $\left(\mathrm{d}_{\mathrm{i}}\right)$, which is the distance from the surface to the nearest nucleus internal to the surface. The color of the points (ranging from blue, green, yellow to red) represents the relative area of the surface characterized by a particular $d_{e} / d_{i}$ couple. The analysis of the fingerprint plot allows for easy investigation of the intermolecular interactions, filtering the contribution from each feature and visualizing the importance of the interaction. The Hirshfeld 
surfaces and fingerprint plots of the three coordination compounds are reported in Figure 7, while the fingerprint plots of the three $\mathrm{PF}_{6}{ }^{-}$anions are reported in Figure 8. In the structure under analysis, $\mathrm{Mol} 1$ and Mol 3 show similar features. In fact, in Figure 7, the light blue streak starting from point $(1.0,1.3)$ representing $\mathrm{H} \cdots \mathrm{F}$ interactions is less evident in $\mathrm{Mol} 2$, indicating that this molecule has less contact with $\mathrm{PF}_{6}{ }^{-}$anions $(16.2 \%$ of the surface) with respect to the other two molecules $(\sim 24 \%)$. Moreover the interaction has a longer distance (the shorter $\mathrm{d}_{\mathrm{e}}$ for $\mathrm{F} \cdots \mathrm{H}$ interactions is $1.1 \AA$ ).

The PF6 3 anion as seen in Figure 8 shows stronger interactions with respect to the other two $\mathrm{PF}_{6}{ }^{-}$, as evidenced by the stronger red streak in its fingerprint plot and shorter $\mathrm{d}_{\mathrm{e}} / \mathrm{d}_{\mathrm{i}}$. This feature is also confirmed by the smaller thermal ellipsoids in the crystal structure (Figure 1) that indicate that the PF6 3 anion is less "disordered" compared to the other two. The three $\left[\operatorname{Ir}(\mathrm{ppy})_{2}(\mathrm{acn})_{2}\right]^{+} / \mathrm{PF}_{6}{ }^{-}$ couples are thus different from each other, even if the three anions and the three cations are the same from the chemical viewpoint. Therefore, it can be concluded that the unusual number of molecules in the asymmetric unit is due to the need of finding a close packing crystal structure with a favorable environment for the three anion/cation couples.
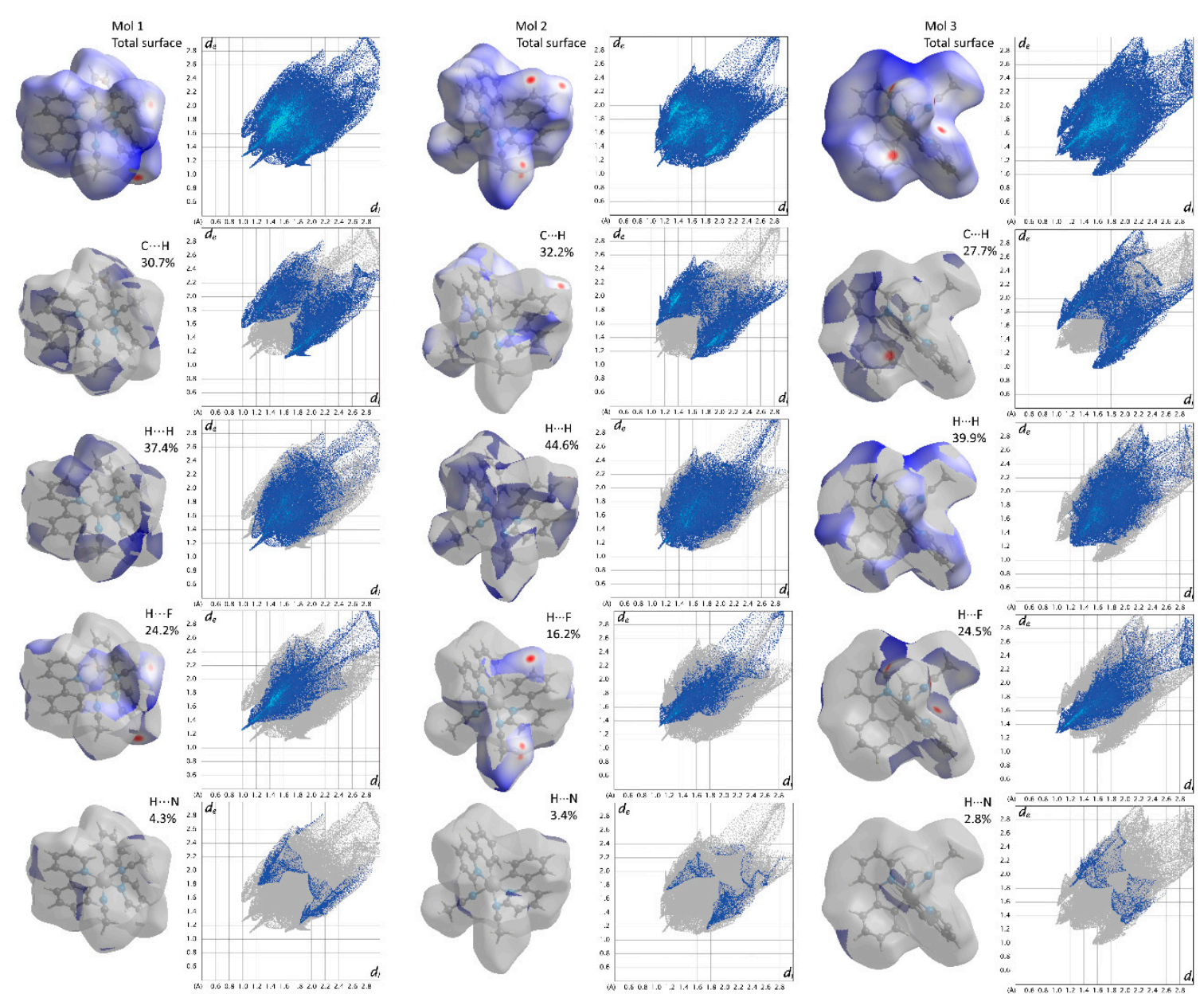

Figure 7. Hirshfeld surface with $\mathrm{d}_{\text {norm }}$ mapped and fingerprint plots of the three $\left[\operatorname{Ir}(\mathrm{ppy})_{2}(\mathrm{acn})_{2}\right]^{+} / \mathrm{PF}_{6}{ }^{-}$ molecules named Mol 1, Mol 2, and Mol 3 for all the interactions (first row) and then decomposed for $\mathrm{H} \cdots \mathrm{H}, \mathrm{C} \cdots \mathrm{H}, \mathrm{C} \cdots \mathrm{N}$, and $\mathrm{F} \cdots \mathrm{C}$ interactions (row 2-5). The color ranges from dark blue to red with increasing frequency (relative area of the surface) corresponding to each kind of interaction. 

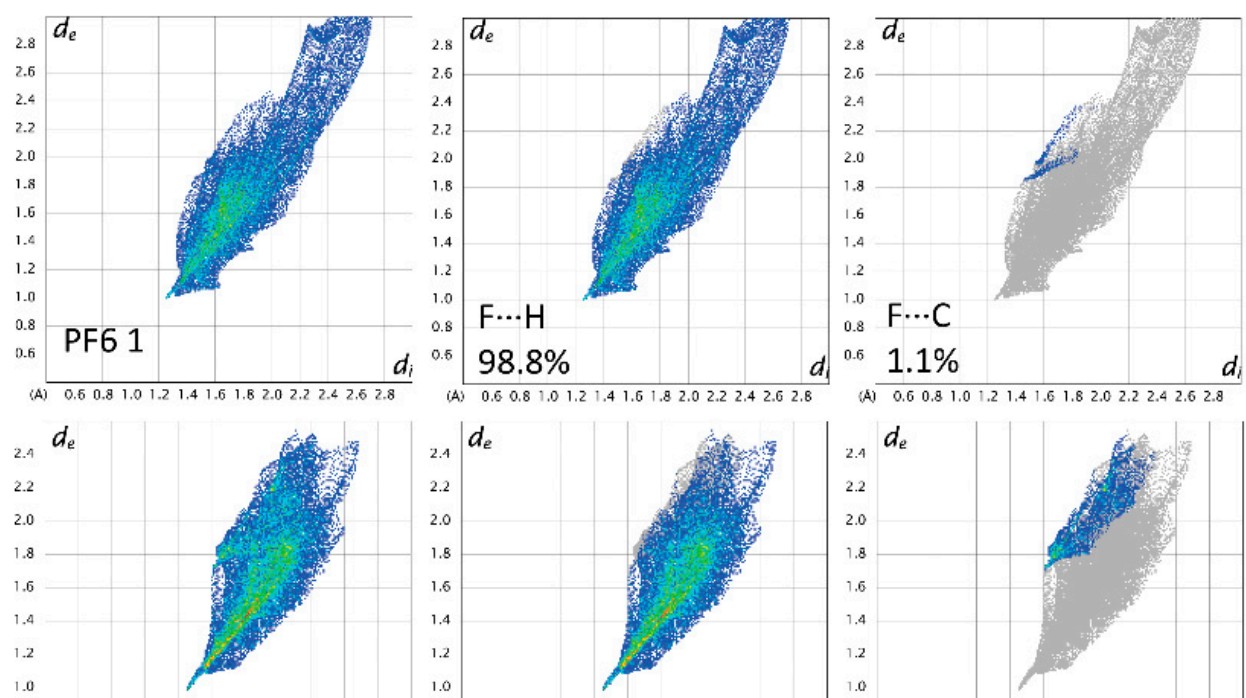

PF6 2
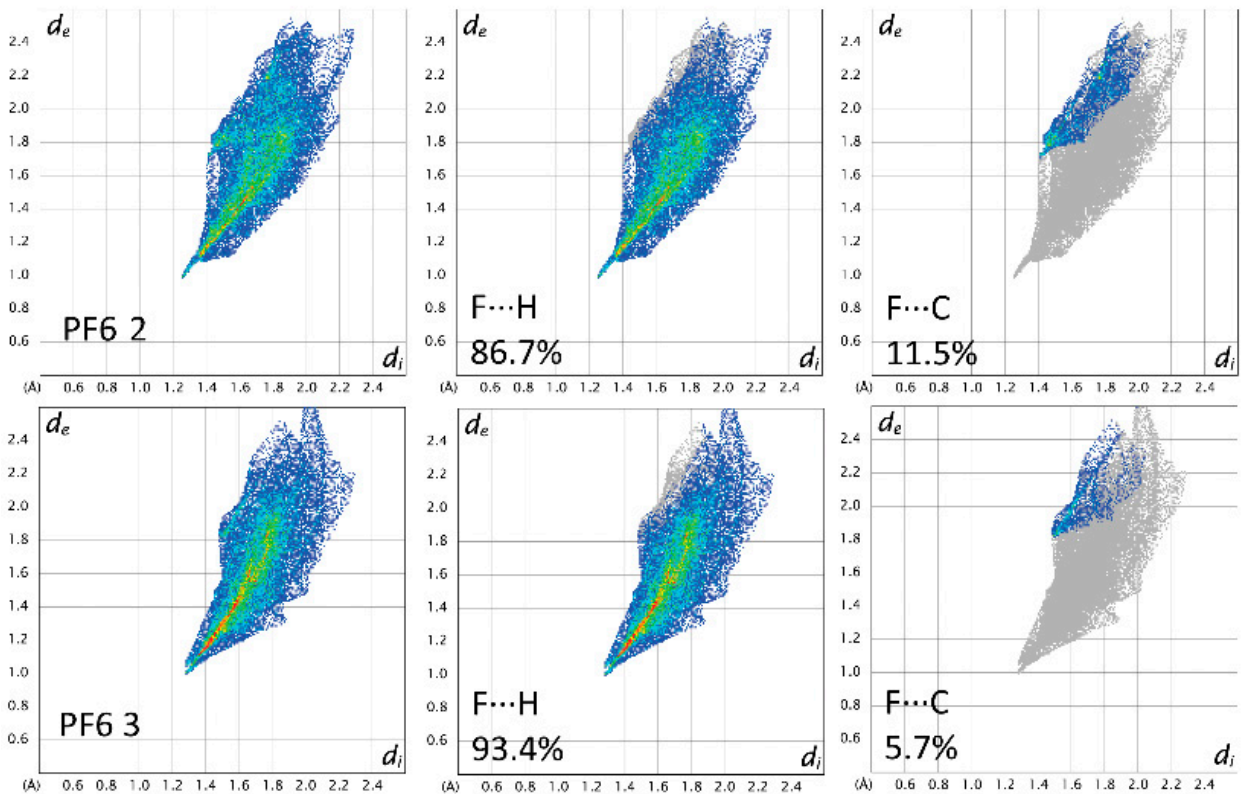

Figure 8. Fingerprint plots from Hirshfeld surface analysis of the three PF6 anion moieties in the packing named PF6 1, PF6 2, and PF6 3 (total surface in the first column and filtered for F...H and F...C). The color ranges from dark blue to red with increasing frequency (relative area of the surface) corresponding to each kind of interaction.

Table 2 reports a summary of the interactions between the moieties, highlighted with color codes congruent with those used in Figures 2 and 3, together with the contact length. Each Iridium complex has one or two contacts with a symmetry equivalent molecule and two contacts with another similar but non-symmetry-equivalent molecule (except for Mol 2). Moreover, they show interactions with at least two non-symmetry-equivalent $\mathrm{PF}_{6}{ }^{-}$ions. By looking at the table, it is clearly visible that $\mathrm{Mol} 2$ has a peculiar set of contacts with respect to Mol 1 and Mol 3 that are more similar. Mol 1 and Mol 3 interact with each other and both with PF6 1. Mol 1 interacts then with PF6 2 and Mol 3 interacts with PF6 3. Mol 3 interacts only with symmetry equivalent moieties and with all the $\mathrm{PF}_{6}{ }^{-}$anions.

Table 2. Short contacts between adjacent moieties.

\begin{tabular}{ccccc}
\hline Moiety $\mathbf{1}$ & Atom $\mathbf{1}$ & Atom $\mathbf{2}$ & Moiety $\mathbf{2}$ & Contact Distance (Å) \\
\hline Mol 1 & C30 & H32 & Mol 1 & 2.852 \\
\hline Mol 1 & H23 & C19 & Mol 3 & 2.818 \\
\hline Mol 1 & H23 & C20 & Mol 3 & 2.635 \\
\hline Mol 1 & H80A & F10 & PF6 2 & 2.359 \\
\hline Mol 1 & H22 & F5 & PF6 1 & 2.346 \\
\hline Mol 1 & H78C & F6 & PF6 1 & 2.618 \\
\hline Mol 1 & C77 & F9 & PF6 2 & 3.159 \\
\hline
\end{tabular}


Table 2. Cont.

\begin{tabular}{ccccc}
\hline Moiety 1 & Atom 1 & Atom 2 & Moiety 2 & Contact Distance (A) \\
\hline Mol 1 & H34 & F12 & PF6 2 & 2.604 \\
\hline Mol 1 & H37 & F12 & PF6 2 & 2.634 \\
\hline Mol 1 & H40 & F9 & PF6 2 & 2.608 \\
\hline Mol 2 & H57 & H49 & Mol 2 & 2.588 \\
\hline Mol 2 & H82B & F8 & Mol 2 & 2.787 \\
\hline Mol 2 & H82B & F3 & PF6 1 & 2.566 \\
\hline Mol 2 & H58 & F11 & PF6 2 & 2.558 \\
\hline Mol 2 & H59 & F16 & PF6 3 & 2.588 \\
\hline Mol 2 & H82A & F17 & PF6 3 & 2.492 \\
\hline Mol 3 & C19 & H23 & Mol 1 & 2.653 \\
\hline Mol 3 & C20 & H23 & Mol 1 & 2.818 \\
\hline Mol 3 & H18 & C10 & Mol 3 & 2.635 \\
\hline Mol 3 & C20 & H76C & Mol 3 & 2.715 \\
\hline Mol 3 & H76A & F1 & PF6 1 & 2.837 \\
\hline Mol 3 & H74C & F3 & PF6 1 & 2.45 \\
\hline Mol 3 & H1 & F1 & PF6 1 & 2.704 \\
\hline Mol 3 & H1 & F4 & PF6 1 & 2.593 \\
\hline Mol 3 & H76B & F15 & PF6 3 & 2.441 \\
\hline Mol 2 & H12 & F18 & PF6 3 & 2.663 \\
\hline Mol 3 & H11 & F18 & PF6 3 & 2.628 \\
\hline Mol 3 & H14 & F20 & PF6 3 & 2.628 \\
\hline & & & & \\
\hline
\end{tabular}

\section{Conclusions}

A crystal of Bis(2-phenylpyridine-C,N')-bis(acetonitrile)iridium(III)hexafluorophosphate was obtained during a voltammetric experiment by a new synthesis route. The novelty consists in the possibility of obtaining the complex at room temperature and without reflux, as reported in the literature [17]. The reaction, despite occurring in the voltammeter, cannot be related to this process since the product was massive in the solution while cyclic voltammetry only samples a small portion of the solution. Its $P-1$ crystal structure showed three anion/cation couples in the asymmetric unit, a feature rather uncommon in the CCDC database. The three coordination complexes are almost identical; however, relevant differences in their environment are highlighted by Hirshfeld surface analysis. In particular, Mol 1 and Mol 3 are interacting with each other beside the interaction with $\mathrm{PF}_{6}{ }^{-}$and have a more similar environment with respect to Mol 2, which is in close contact with its symmetry equivalent moieties. It can be concluded that symmetry is sacrificed to obtain a more stable packing, maximizing aromatic clustering and $\left[\operatorname{Ir}(\mathrm{ppy})_{2}(\mathrm{acn})_{2}\right]^{+} / \mathrm{PF}_{6}{ }^{-}$interactions for this rigid and rather asymmetric molecule. The driving force of the packing is the clustering of the aromatic rings and the maximization of acetonitrile: $\mathrm{PF}_{6}{ }^{-}$interactions.

Supplementary Materials: The following are available online at http://www.mdpi.com/2073-4352/9/12/617/s1, Table S1: Crystal data and structure refinement for $\left[\operatorname{Ir}(\mathrm{ppy})_{2}(\mathrm{acn})_{2}\right]^{+} / \mathrm{PF}_{6}{ }^{-}$; Table S2: Atomic coordinates $\left(\times 10^{4}\right)$ and equivalent isotropic displacement parameters $\left(\AA^{2} \times 10^{3}\right)$.; Table S3: Anisotropic displacement parameters $\left(\AA^{2} \times 10^{3}\right)$ for $\left[\operatorname{Ir}(\mathrm{ppy})_{2}(\mathrm{acn})_{2}\right]^{+} / \mathrm{PF}_{6}{ }^{-}$.

Author Contributions: Conceptualization, M.M. and E.C.; methodology, E.F.; formal analysis, E.C.; investigation, M.M., E.F. and G.V.; writing—original draft preparation, M.M. and E.C.; writing—review and editing, C.B. and G.V. 
Funding: This research was funded by FINPIEMONTE within the Programma Pluriennale Attività Produttive308 2015/2017 Misura3.1 "Contratto d'Insediamento" for the project "Sviluppo di tecnologia applicata alla costruzione di cabine radiografiche per l'ispezione di componenti per il settore industriale e aerospaziale" (project code310 208-105).

Conflicts of Interest: The authors declare no conflict of interest.

\section{References}

1. Nonoyama, M. Benzo[h]quinolin-10-yl-N Iridium(III) Complexes. Bull. Chem. Soc. Jpn. 1974, 47, 767-768. [CrossRef]

2. King, K.A.; Spellane, P.J.; Watts, R.J. Excited-state properties of a triply ortho-metalated iridium(III) complex. J. Am. Chem. Soc. 1985, 107, 1431-1432. [CrossRef]

3. Sprouse, S.; King, K.A.; Spellane, P.J.; Watts, R.J. Photophysical effects of metal-carbon. sigma. bonds in ortho-metalated complexes of iridium(III) and rhodium(III). J. Am. Chem. Soc. 1984, 106, 6647-6653. [CrossRef]

4. Lamansky, S.; Djurovich, P.; Murphy, D.; Abdel-Razzaq, F.; Kwong, R.; Tsyba, I.; Bortz, M.; Mui, B.; Bau, R.; Thompson, M.E. Synthesis and Characterization of Phosphorescent Cyclometalated Iridium Complexes. Inorg. Chem. 2001, 40, 1704-1711. [CrossRef]

5. Lamansky, S.; Djurovich, P.; Murphy, D.; Abdel-Razzaq, F.; Lee, H.-E.; Adachi, C.; Burrows, P.E.; Forrest, S.R.; Thompson, M.E. Highly Phosphorescent Bis-Cyclometalated Iridium Complexes: Synthesis, Photophysical Characterization, and Use in Organic Light Emitting Diodes. J. Am. Chem. Soc. 2001, 123, 4304-4312. [CrossRef]

6. Gao, R.; Ho, D.G.; Hernandez, B.; Selke, M.; Murphy, D.; Djurovich, P.I.; Thompson, M.E. Bis-cyclometalated Ir(III) Complexes as Efficient Singlet Oxygen Sensitizers. J. Am. Chem. Soc. 2002, 124, 14828-14829. [CrossRef] [PubMed]

7. Chang, C.-J.; Yang, C.-H.; Chen, K.; Chi, Y.; Shu, C.-F.; Ho, M.-L.; Yehc, Y.-S.; Chou, P.-T. Color tuning associated with heteroleptic cyclometalated $\mathrm{Ir}(\mathrm{III})$ complexes: Influence of the ancillary ligand. Dalt. Trans. 2007, 21, 1881-1890. [CrossRef] [PubMed]

8. Volpi, G.; Garino, C.; Salassa, L.; Fiedler, J.; Hardcastle, K.I.; Gobetto, R.; Nervi, C. Cationic Heteroleptic Cyclometalated Iridium Complexes with 1-Pyridylimidazo[1,5- $\alpha$ ]pyridine Ligands: Exploitation of an Efficient Intersystem Crossing. Chem. A Eur. J. 2009, 15, 6415-6427. [CrossRef] [PubMed]

9. Housecroft, C.E.; Constable, E.C. Over the LEC rainbow: Colour and stability tuning of cyclometallated Iridium(III) complexes in light-emitting electrochemical cells. Coord. Chem. Rev. 2017, 350, 155-177. [CrossRef]

10. Longhi, E.; De Cola, L. Iridium(III) Complexes for OLED Application. In Iridium(III) in Optoelectronic and Photonics Applications; John Wiley \& Sons Ltd.: Hoboken, NJ, USA, 2017; pp. 205-274. [CrossRef]

11. Pashaei, B.; Karimi, S.; Shahroosvand, H.; Abbasi, P.; Pilkington, M.; Bartolotta, A.; Fresta, E.; Fernandez-Cestau, J.; Costa, R.D.; Bonaccorso, F. Polypyridyl ligands as a versatile platform for solid-state light-emitting devices. Chem. Soc. Rev. 2019, 48, 5033-5139. [CrossRef]

12. Lo, K.K.W.; Chung, C.K.; Lee, T.K.M.; Lui, L.H.; Tsang, K.H.K.; Zhu, N. New Luminescent Cyclometalated Iridium(III) Diimine Complexes as Biological Labeling Reagents. Inorg. Chem. 2003, 42, 6886-6897. [CrossRef] [PubMed]

13. Flamigni, L.; Barbieri, A.; Sabatini, C.; Ventura, B.; Barigelletti, F. Photochemistry and Photophysics of Coordination Compounds: Iridium BT - Photochemistry and Photophysics of Coordination Compounds II. Top. Curr. Chem. 2007, 281, 143-203. [CrossRef]

14. Campagna, S.; Putoriero, F.; Nastasi, F.; Bergamini, G.; Balzani, V. Photochemistry and Photophysics of Coordination Compounds: Ruthenium. Top. Curr. Chem. 2007, 280, 117-214.

15. Costa, R.D.; Ortí, E.; Bolink, H.J.; Monti, F.; Accorsi, G.; Armaroli, N. Luminescent ionic transition-metal complexes for light-emitting electrochemical cells. Angew. Chem. Int. Ed. 2012, 51, 8178-8211. [CrossRef] [PubMed]

16. Fresta, E.; Volpi, G.; Garino, C.; Barolo, C.; Costa, R.D. Contextualizing yellow light-emitting electrochemical cells based on a blue-emitting imidazo-pyridine emitter. Polyhedron 2018, 140, 129-137. [CrossRef]

17. McGee, K.A.; Mann, K.R. Selective low-temperature syntheses of facial and meridional tris-cyclometalated iridium(III) complexes. Inorg. Chem. 2007, 46, 7800-7809. [CrossRef] 
18. Steed, J.W. Should solid-state molecular packing have to obey the rules of crystallographic symmetry? CrystEngComm 2003, 5, 169-179. [CrossRef]

19. Steed, K.M.; Steed, J.W. Packing Problems: High Z' Crystal Structures and Their Relationship to Cocrystals, Inclusion Compounds, and Polymorphism. Chem. Rev. 2015, 115, 2895-2933. [CrossRef]

20. Lemmerer, A.; Fernandes, M.A. Adventures in co-crystal land: High Z', stoichiometric variations, polymorphism and phase transitions in the co-crystals of four liquid and solid cyclic carboxylic acids with the supramolecular reagent isonicotinamide. New J. Chem. 2012, 36, 2242-2252. [CrossRef]

21. Taylor, R.; Cole, J.C.; Groom, C.R. Molecular Interactions in Crystal Structures with Z' > 1. Cryst. Growth Des. 2016, 16, 2988-3001. [CrossRef]

22. Rajnikant; Gupta, V.K.; Kapoor, K.; Kumar, S.; Dhar, K.L. X-ray Structure Analysis Online Multiple Molecules in the Crystallographic Asymmetric Unit of (Z)-3-(3-Chlorophenyl)-2-phenyl acrylic acid. X-ray Struct. Anal. Online 2012, 28, 9-10.

23. Ciborska, A.; Conterosito, E.; Milanesio, M.; Kazimierczuk, K.; Rzymowska, K.; Brzozowski, K.; Dołęga, A. The Syntheses and Crystal Structures of the First Disiloxane-1,3-dithiol and Its Cadmium Complex. Eur. J. Inorg. Chem. 2015, 2015, 3059-3065. [CrossRef]

24. Conterosito, E.; Magistris, C.; Barolo, C.; Croce, G.; Milanesio, M. Synthesis, characterization and crystal structure of 6-Chloro-4,4'-dimethyl-2,2' -bipyridine and 4,4'-Dimethyl 2,2'-bipyridine N-Oxide. J. Mol. Struct. 2016, 1107, 337-343. [CrossRef]

25. Toson, V.; Milanesio, M.; Conterosito, E. Crystal packing and layered morphology relationships in naphthalene sulfonate compounds. Zeitschrift für Kristallographie-Crystalline Materials 2017, 232, 463-469. [CrossRef]

26. Spackman, M.A.; Jayatilaka, D. Hirshfeld surface analysis. CrystEngComm 2009, 11, 19-32. [CrossRef]

27. Spackman, M.A.; McKinnon, J.J. Fingerprinting intermolecular interactions in molecular crystals. CrystEngComm 2002, 4, 378. [CrossRef]

28. McKinnon, J.J.; Jayatilaka, D.; Spackman, M.A. Towards quantitative analysis of intermolecular interactions with Hirshfeld surfaces. Chem. Commun. 2007, 37, 3814-3816. [CrossRef]

29. McKinnon, J.J.; Spackman, M.A.; Mitchell, A.S. Novel Tools for Visualizing and Exploring Intermolecular Interactions in Molecular Crystals. Acta Crystallogr. B 2004, 60, 627-668. [CrossRef]

30. Tankov, I.; Yankova, R. Mechanistic investigation of molecular geometry, intermolecular interactions and spectroscopic properties of pyridinium nitrate. Spectrochim. Acta Part A Mol. Biomol. Spectrosc. 2019, 219, 53-67. [CrossRef]

31. Tankov, I.; Yankova, R. Hirshfeld surface, DFT vibrational (FT-IR) and electronic (UV-vis) studies on 4-amino-1H-1,2,4-triazolium nitrate. J. Mol. Struct. 2019, 1179, 581-592. [CrossRef]

32. Rigaku Oxford Diffraction, CrysAlisPro Software System, version 1.171.38.46; Rigaku Corporation: Wroclaw, Poland, 2015.

33. Burla, M.C.; Caliandro, R.; Carrozzini, B.; Cascarano, G.L.; Cuocci, C.; Giacovazzo, C.; Mallamo, M.; Mazzone, A.; Polidori, G. Crystal structure determination and refinement via SIR2014. J. Appl. Crystallogr. 2015, 48, 306-309. [CrossRef]

34. Sheldrick, G.M. Crystal structure refinement with SHELXL. Acta Cryst. 2015, C71, 3-8. [CrossRef]

35. Wolff, S.K.; Grimwood, D.J.; McKinnon, J.J.; Jayatilaka, D.; Spackman, M.A. CrystalExplorer; University of Western Australia: Crawley, Australia, 2017.

36. Macrae, C.F.; Edgington, P.R.; McCabe, P.; Pidcock, E.; Shields, G.P.; Taylor, R.; Towler, M.; van de Streek, J. Mercury: Visualization and analysis of crystal structures. J. Appl. Cryst. 2006, 39, 453-457. [CrossRef]

37. Leone, L.; Esteban-Gómez, D.; Platas-Iglesias, C.; Milanesio, M.; Tei, L. Accelerating water exchange in Gd III -DO3A-derivatives by favouring the dissociative mechanism through hydrogen bonding. Chem. Commun. 2019, 55, 513-516. [CrossRef] [PubMed]

38. Capillas, C.; Tasci, E.S.; de la Flor, G.; Orobengoa, D.; Perez-Mato, J.M.; Aroyo, M.I. A new computer tool at the Bilbao Crystallographic Server to detect and characterize pseudosymmetry. Zeitschrift für Kristallographie-Crystalline Materials 2011, 226, 186-196. [CrossRef]

39. Conifer, C.M.; Taylor, R.A.; Law, D.J.; Sunley, G.J.; White, A.J.P.; Britovsek, G.J.P. First metal complexes of 6,6'-dihydroxy-2,2'-bipyridine: From molecular wires to applications in carbonylation catalysis. Dalt. Trans. 2011, 40, 1031-1033. [CrossRef] 
40. Sun, B.; Guan, J.-X.; Xu, L.; Yu, B.-L.; Jiang, L.; Kou, J.-F.; Wang, L.; Ding, X.-D.; Chao, H.; Ji, L.-N. DNA Condensation Induced by Ruthenium(II) Polypyridyl Complexes $\left[\mathrm{Ru}(\mathrm{bpy})_{2}(\mathrm{PIPSH})\right]^{2+}$ and $\left[\mathrm{Ru}(\mathrm{bpy})_{2}\right.$ (PIPNH)] ${ }^{2+}$. Inorg. Chem. 2009, 48, 4637-4639. [CrossRef]

41. Akine, S.; Nagumo, H.; Nabeshima, T. Hierarchical Helix of Helix in the Crystal: Formation of Variable-Pitch Helical $\pi$-Stacked Array of Single-Helical Dinuclear Metal Complexes. Inorg. Chem. 2012, 51, 5506-5508. [CrossRef]

42. Wah, H.L.K.; Postel, M.; Tomi, F.; Mordenti, L.; Ballivet-Tkatchenko, D.; Dahan, F.; Urso, F. Reaction of chlorobisnitrosyliron dimer with bidentate nitrogen ligands (2,2'-bipyridine, 4,4'-dimethyl 2,2'-bipyridine and 1,10-phenanthroline) X-ray structure of $\left[\mathrm{Fe}(\mathrm{bpy})_{3}\right]\left[\mathrm{Fe}(\mathrm{NO})_{2} \mathrm{Cl}_{2}\right]_{2}$. New J. Chem. 1991, 15, 629.

43. Laws, K.; Eskandari, A.; Lu, C.; Suntharalingam, K. Highly Charged, Cytotoxic, Cyclometalated Iridium(III) Complexes as Cancer Stem Cell Mitochondriotropics. Chem. A Eur. J. 2018, 24, 15205-15210. [CrossRef]

44. Zheng, Y.; Harms, K.; Zhang, L.; Meggers, E. Enantioselective Alkynylation of 2-Trifluoroacetyl Imidazoles Catalyzed by Bis-Cyclometalated Rhodium(III) Complexes Containing Pinene-Derived Ligands. Chem. A Eur. J. 2016, 22, 11977-11981. [CrossRef] [PubMed]

45. Heeg, M.J.; Kroener, R.; Deutsch, E. IUCr Structure of cis-bis(acetonitrile)bis(2,2'-bipyridine)ruthenium(II) hexafluorophosphate, [Ru(C2H3N)2(C10H8N2)2](PF6)2. Acta Cryst. 1985, C41, 684-686. [CrossRef]

46. Xu, F.; Huang, W. IUCr Redetermination of cis-diacetonitrilebis(2,2'-bipyridine)ruthenium(II) hexafluorophosphate. Acta Cryst. 2007, E63, m2114. [CrossRef]

(C) 2019 by the authors. Licensee MDPI, Basel, Switzerland. This article is an open access article distributed under the terms and conditions of the Creative Commons Attribution (CC BY) license (http://creativecommons.org/licenses/by/4.0/). 